an Australian parent's magazine and of 455 attending National Childbirth Trust meetings who had responded to a query about their experience of epidural anaesthesia and subsequent effects. Improvements in anaesthetic technique, especially the use of different needles, may alter the risk of spinal headache. Nevertheless, in view of the recent increase in use of subarachnoid anaesthesia for caesarean section, further examination of the association with spinal headaches, even though based on small numbers, is urgently required.

Paraesthesias in the legs and lower back were also mentioned by Kitzinger. ${ }^{9}$ Our data on numbness or tingling in the legs or lower back were elicited only in response to an open question so may have underestimated the incidence. Such data, for the same reason, are also more susceptible to reporting bias among women who had an epidural anaesthesia. Nevertheless, the difference was highly significant and unexplained by backache and deserves further consideration.

Visual disturbances and dizziness or fainting were not specifically mentioned by Kitzinger, although some women described a kind of sensory confusion. ${ }^{9}$ We found that both of these symptoms were associated with migraine, and the association between epidural anaesthesia and visual disturbances seemed to be secondary to the association with migraine. For dizziness or fainting, however, it was less clear whether the same applied. Further research is needed to elucidate this point.

We have identified independent associations between several long term symptoms after childbirth and epidural anaesthesia. Care was taken to avoid reporting bias and there was no evidence of enhanced reporting of other symptoms by women who had epidural anaesthesia ${ }^{67}$ Nevertheless, a hidden factor

might account for these associations. Further examination with different investigational methods including randomised trials, is needed. The impact of the symptoms on the women's lives also needs to be assessed. Epidural analgesia is unquestionably the most effective form of pain relief available for labour ${ }^{10-12}$ and as such is used by large numbers of women. ${ }^{13}$ These next stages of inquiry are therefore urgent.

Dr J Selwyn Crawford participated in the original design of the study until his death in August 1988. We thank the women who took part in the study. The work was funded by a grant from the Department of Health.

1 Crawford JS. Lumbar epidural block in labour: a clinical analysis. Br $\mathcal{F}$ Anaest 1972; 44:66-70

2 Crawford JS. Principles and practice of obstetric anaesthesia. 5th ed. Oxford: Blackwell Scientific, 1985

3 Crawford JS. Some maternal complications of epidural analgesia for labour Analgesia 1985;40:1219-25.

4 Moore J, Murraghan GA, Lewis MA. A clinical evaluation of the materna effects of extradural analgesia for labour. Anaesthesia 1974;29:537-40.

5 Ramanathan S. Obstetric anaesthesia. Philadelphia: Lea and Febiger, 1988.

6 MacArthur C, Lewis M, Knox EG, Crawford JS. Epidural anaesthesia and long term backache after childbirth. BMF 1990:301:9-12.

7 MacArthur C, Lewis M, Knox EG. Health after childbirth. London: HMSO, 1991.

8 Brownridge $P$. The management of headache following accidental dural puncture in obstetric patients. Anaesth Intensive Care 1983;11:4-15.

9 Kitzinger S. Some women's experiences of epidurals: a descriptive study. London National Childirinh Trust, 1987.

10 Morgan BM, Bulpitt CJ, Clifton P, Lewis PJ. Analgesia and satisfaction in hildbirth. Lancet 1982;ii:808-10.

11 Robinson JO, Rosen M, Evans JM, Revill S, David H, Rees GAD. Materna opinion about analgesia for labour. A controlled trial between epidural block and intra-muscular pethidine combined with inhalation. Anaesthesia 1980 35:1173-81

12 Philipsen T, Jensen NH. Maternal opinion about analgesia in labour and delivery. A comparison of epidural blockade and intra-muscular pethidine. Eur J Obstet Gynecol Reprod Biol 1990;34:205-10.

13 Hibbard BM, Scott DB. The availability of epidural anaesthesia and analgesia in obstetrics. Br $\mathcal{F}$ Obstet Gynaecol 1990;97:402-5.

(Accepted 10 March 1992)

\title{
Treatment of natal cleft sinus: a prospective clinical and economic evaluation
}

\section{H T Khawaja, S Bryan, P C Weaver}

Department of Surgery, St Mary's Hospital,

Portsmouth

H T Khawaja, FRCS, senior registrar

PC Weaver, FRCS,

consultant

Health Economics Research Group, Brunel

University, Uxbridge, Middlesex

S Bryan, MSC, research fellow

Correspondence to:

Mr H T Khawaja,

Department of Surgery

(Firm III Office), King's

College Hospital, London

SE5 9RS.

BMF 1992;304:1282-3
Many surgical techniques are used for treating natal cleft sinus, yet recurrence rates are high. ${ }^{1}$ This study evaluated two commonly used treatments: excision and primary closure, and excision and healing by secondary intention.

\section{Patients, methods, and results}

Among adult patients with symptomatic natal cleft sinus, those with abscess formation or diabetes mellitus, those on steroids, and those judged unsuitable for day case surgery were excluded from the trial. Over 49 months, 46 consecutive patients entered the trial and were randomly allocated to a treatment group by a system of sequentially numbered opaque sealed envelopes.

Surgery was undertaken under general anaesthetic. Following excision, primary closure was achieved with deep mattress prolene sutures and the patients discharged home on the same day (group 1), or the cavity was packed with gauze soaked with aqueous proflavine; the pack was changed daily and the patient allowed home when packing was tolerable without parenteral analgesia (group 2).

All patients were reviewed weekly until healing occurred and also six and 12 months later. Healing was defined as complete epithelialisation of the operative site. In group 2 the proflavine pack was changed daily for the first week and replaced by a silicone foam, which was renewed weekly until healing occurred. In group 1 the sutures were removed on the 14th postoperative day. If primary closure failed the wound was allowed to heal by granulation.

Length of admission, outpatient visits, district nurse visits, days off work, days to complete healing, and recurrence at six and 12 months were measured. An "intention to treat" analysis ${ }^{2}$ was used for between group comparisons. Confidence intervals for population differences between medians were calculated based on the median differences between the unpaired samples of observations.

The table compares the groups and describes the outcome variables. In group 2 all patients had complete healing of the wound with no recorded complications.

Outcome of treatment of natal cleft sinus by excision and primary closure or excision and secondary healing. Values are medians unless otherwise stated

\begin{tabular}{lccc}
\hline & $\begin{array}{c}\text { Group 1- } \\
\text { primary } \\
\text { closure } \\
(\mathrm{n}=23)\end{array}$ & $\begin{array}{c}\text { Group 2- } \\
\text { secondary } \\
\text { healing } \\
(\mathrm{n}=23)\end{array}$ & $\begin{array}{c}\text { Median difference } \\
\text { between groups } \\
(95 \% \text { confidence } \\
\text { intervals })\end{array}$ \\
\hline Age (years) & 25 & 23 & NA \\
Sex (male:female ratio) & $19: 4$ & $17: 6$ & NA \\
$\begin{array}{l}\text { No of pits } \\
\text { No of days in hospital }\end{array}$ & 2 & 2 & NA \\
$\begin{array}{l}\text { No of days to healing } \\
\text { No of days off work }\end{array}$ & $14 \dagger$ & 3 & NA \\
$\begin{array}{l}\text { No of outpatient visits } \\
\text { No of visits by district } \\
\text { nurse }\end{array}$ & 2 & 41 & $-23(-28$ to -20$)$ \\
\hline
\end{tabular}

NA $=$ not applicable

Day case surgery.

† Sutures removed on the 14th postoperative day. 
In group 1, 17 of 23 patients (74\%) had no complications. The wound broke down in four patients after removal of sutures. Although these patients had no clinical evidence of infection, wound cultures grew aerobic and anaerobic organisms in three of the four cases. Two other patients required early removal of sutures on the second and ninth postoperative days for wound haematoma and wound infection respectively. There was no evidence of recurrence in either group at six and 12 months follow up.

\section{Comment}

Successful day case excision and primary closure of natal cleft sinus is feasible and offers earlier healing than excision and healing by secondary intention. Although primary closure was not always successful, the time to complete healing of unsuccessful cases was not significantly different from that of the secondary healing group (median difference $-4 ; 95 \%$ confidence interval -10 to 3 ).

The failure rate in group 1 is higher than that reported elsewhere.' Four of the six patients who failed to heal had bacteriological evidence of wound infection. Kronborg $e t a l$ have reported that the prophylactic use of clindamycin reduced healing time after primary closure. ${ }^{3}$ None of our patients received prophylactic antibiotics, and no subcutaneous sutures were used. Use of the outpatient department and district nurse was lower in group 1 than group 2. (Further clinical details can be obtained from the author.)

This study shows that excision and primary closure of uncomplicated natal cleft sinus is less costly and more effective than secondary healing. Although the procedure was unsuccessful for some patients, secondary healing occurred without any increase in the overall time to healing compared with secondary healing only. Widespread use of primary closure could reduce health care expenditure and patients' time off work. Further studies are required to compare excision and primary closure to other potentially cost effective methods of treatment.

We are grateful to surgeons in Portsmouth District Health Authority for allowing us to study their patients.

Allen-Mersh TG. Pilonidal sinus: finding the right track for treatment. BrF Surg 1990;77:123-32.

2 Gardner MJ, Altman DG. Statistics with confidence. London: British Medical Journal, 1990 .

3 Kronborg O, Christensen KI, Zimmermann-Nielsen O. Chronic pilonidal disease: a randomised trial with complete 3-year follow up. Br $\mathcal{F}$ Surg disease: a rand

(Accepted 11 November 1991)

\section{Use of Lucozade and glucagon by ambulance staff for treating hypoglycaemia}

\section{J M Steel, J Allwinkle, R Moffat, D J Carrington}

Department of Diabetes, Royal Infirmary of Edinburgh, Edinburgh EH3 9YW

J M Steel, associate specialist J Allwinkle, diabetic liaison nurse

Scottish Ambulance Service, Fife, Lothian and Borders Area, Edinburgh EH10 5SA

R Moffat, area training officer D J Carrington, chief ambulance officer

$B M 7$ 1992;304:1283-4
Severe hypoglycaemia is a serious and much feared complication of insulin treatment. Intensive treatment with insulin makes it more likely to occur. ${ }^{1}$ Hypoglycaemia may cause physical damage and transient or permanent neurological damage, and occasionally it causes cerebral oedema and death.

In an attempt to reduce morbidity and hospital admissions we trained all ambulance staff (not only "paramedics") how to measure blood glucose concentrations and treat hypoglycaemia with oral glucose and subcutaneous glucagon.

\section{Methods and results}

All ambulance staff in the Lothian region were instructed by a series of tutorials and demonstrations how to recognise and treat hypoglycaemia. They were taught how to measure blood glucose concentrations with test strips and instructed to do this for any patient they thought could be hypoglycaemic. If the concentration was less than $4 \mathrm{mmol} / \mathrm{l}$ they were instructed to give a tumbler of Lucozade (oral glucose); if this was impossible they were to give $1 \mathrm{mg}$ of glucagon subcutaneously, followed on recovery by Lucozade. Patients were taken to an accident and emergency
Condition of 103 diabetic patients with severe hypoglycaemia on arrival of ambulance staff and outcome after treatment with oral or subcutaneous glucose

\begin{tabular}{|c|c|c|c|c|c|c|}
\hline & & \multirow[b]{2}{*}{ Confused } & \multirow[b]{2}{*}{ Agitated } & \multicolumn{3}{|c|}{ Unconscious } \\
\hline & & & & Fitting & $\begin{array}{l}\text { Responding } \\
\text { to pain }\end{array}$ & $\begin{array}{l}\text { Not } \\
\text { responding } \\
\text { to pain }\end{array}$ \\
\hline Total No & 103 & 68 & 62 & 20 & 31 & 8 \\
\hline No not taken to hospital & 24 & 13 & 18 & 4 & 5 & 1 \\
\hline $\begin{array}{l}\text { No given no treatment or oral } \\
\text { treatment }\end{array}$ & 62 & 46 & 34 & 13 & 20 & 4 \\
\hline No given intravenous treatment & 10 & 6 & 5 & 1 & 3 & 2 \\
\hline
\end{tabular}

department unless they signed a form refusing to go. Clinical details were recorded on 153 calls in which the patients were suspected of being hypoglycaemic.

There were 103 hypoglycaemic episodes in 88 insulin treated diabetic patients ( 32 women, 56 men) over the nine month period of the study. Twenty six episodes were treated with Lucozade only and 76 with glucagon. One patient was so uncooperative that treatment was impossible. Twenty four patients recovered quickly and refused to go to hospital. Sixty two were discharged from the accident and emergency department after either no treatment, oral glucose, or "tea and toast." Ten were given intravenous glucose and discharged without admission. Seven were admitted but in no case was this for further treatment of hypoglycaemia. The responses of the patients were not related to their clinical state (table). In eight episodes (seven men) alcohol was mentioned as a relevant factor.

Two episodes of hypoglycaemia occurred in diabetic patients receiving a sulphonylurea drug. One was treated with Lucozade and the other with glucagon; neither required hospital treatment.

Seventeen diabetic patients were not hypoglycaemic. Five were hyperglycaemic and the others had problems unrelated to diabetes.

Thirty one patients were later found not to be diabetic. Six of these, however, were hypoglycaemic. Two were wives of diabetics who had taken an intentional overdose of insulin: one recovered after Lucozade; the other was the only patient in the series requiring inpatient treatment for hypoglycaemia. The four other hypoglycaemic patients were intoxicated with alcohol.

\section{Comment}

Ambulance staff in Cardiff have reported the use of intravenous dextrose in the management of hypoglycaemia. ${ }^{2}$ This can be difficult in a restless or convulsing patient and there is a risk of venous sclerosis of precious veins and of tissue necrosis. These disadvantages greatly outweigh the advantage of a very slightly faster recovery. ${ }^{34} \mathrm{~A}$ report from Norwich records the experience of paramedics giving glucagon to 28 patients, ${ }^{5}$ but more can be treated if all ambulance staff are involved. 